\title{
SHG relaxation behaviour in m-nitroaniline doped PMMA guest-host system
}

\author{
R.K. Goyal ${ }^{1 \star}$, S.R. Damkale ${ }^{2}$, U.P. Mulik ${ }^{2}$, Y.S. Negi ${ }^{3}$, J. W. Dadge ${ }^{4}$, R.C. Aiyer ${ }^{5}$ \\ ${ }^{I}$ Department of Metallurgy and Materials Science, College of Engineering, Shivaji Nagar, \\ Pune 411 005, India \\ ${ }^{2}$ Centre for Materials for Electronics Technology, Department of Information Technology, \\ Govt. of India, Panchwati, Off Pashan Road, Pune 411008, India \\ ${ }^{3}$ Polymer Science and Technology Laboratory, Department of Paper Technology, \\ Indian Institute of Technology, Roorkee, Saharanpur campus, Saharanpur 247 001, U.P., India \\ ${ }^{4}$ Department of Physics, College of Engineering, Shivaji Nagar, Pune 411 005, India \\ ${ }^{5}$ Laser Laboratory, Department of Physics, University of Pune, Pune 411 007, India
}

*Corresponding author. Tel: (+91) 20 25507275; Fax: (+91) 20 25507299; E-mail: rkgoyal72@yahoo.co.in

Received: 10 Aug 2010, Revised: 25 Sept 2010 and Accepted: 27 Sept 2010

\section{ABSTRACT}

In present work, we have reported the second harmonic generation (SHG) property on the Guest-Host system based on optical grade poly(methyl methacrylate) (PMMA) and m-Nitroaniline (m-NA) for their use in optoelectronic devices. SHG signal of the m-NA doped PMMA freestanding films was determined using Nd:YAG laser by varying input energy from $6 \mathrm{~mJ}$ to $18 \mathrm{~mJ}$. For evaluating SHG, films were poled at various temperatures to align the m-NA guest molecules in PMMA host matrix. Doped films were also characterized isothermally by thermogravimetric analysis (TGA) to get the information about loss of m-NA molecules at poling temperatures. It was found that there is no change in glass transition temperature. SHG intensity increases as the poling temperature increases. However, SHG signal intensity decreases as the decay time of poled films increases. After one week of poling more than half of the original SHG intensity is retained. The decay in SHG intensity might be attributed to the relaxation of m-NA molecules from thermodynamic unstable state to the equilibrium state. Copyright (C) 2010 VBRI press.

Keywords: Guest-host system, SHG, m-nitroaniline, PMMA, relaxation.

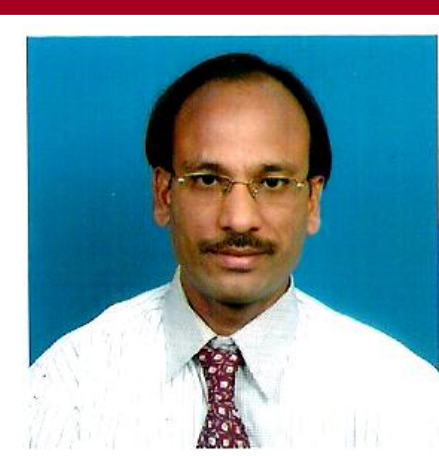

Professor in 2008 . He has industrial an 14 years. He has published over 60 papers in national and international peer-reviewed journals and conferences. His main research areas are polymer composites/nanocomposites, nanomaterials, characterization of materials, electronic materials, structure-properties relationship etc.

\begin{abstract}
Rajendra Kumar Goyal received Ph.D. in Materials Science from the Indian Institute of Technology Bombay, Mumbai, India in 2007. He obtained B.E. in Metallurgical Engineering from Malviya Regional Engineering College (now, NIT) Jaipur, University of Rajasthan, Jaipur, India in 1996. He joined Department of Metallurgy and Materials Science, College of Engineering, Science, College of Engineering, Pune (COEP), India as Asse than of
\end{abstract}

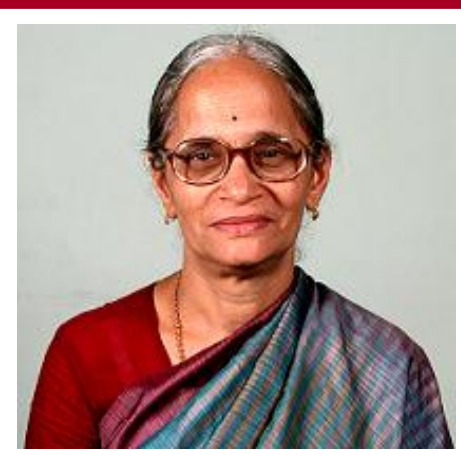

Shubhangi R. Damkale received B.Sc. (Tech.) in Technology of Pigments, Paints and Varnishes from University Institute of Chemical Technology (formerly UDCT), Matunga, Mumbai University, India in 1996. She received M.Sc. (P.P.P.R) in Analytical Chemistry from University of Pune, India in 2007. She has been working as scientific staff in Centre for Materials for Electronics Technology (C-MET), Department of Information Technology, Govt. of India, Pune, since 1998. Her main 

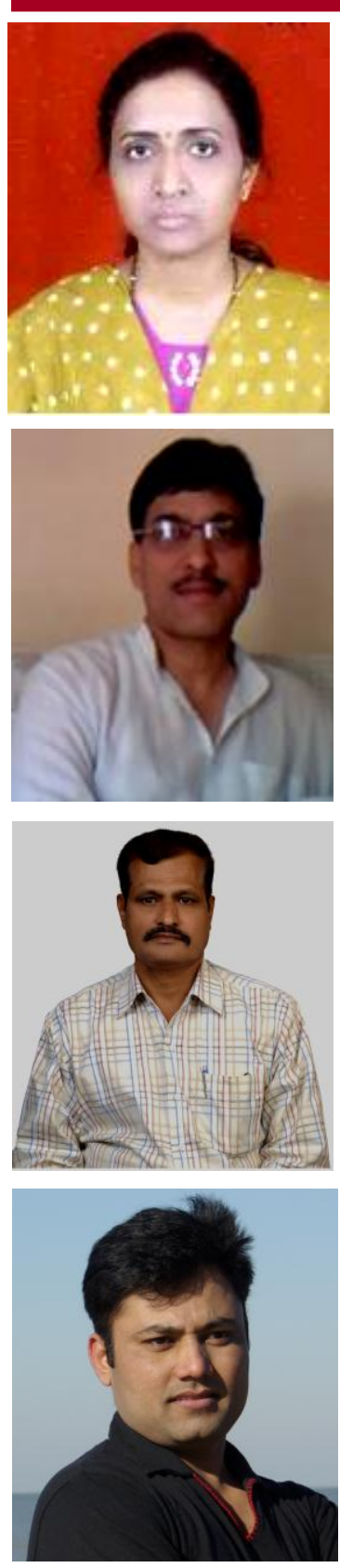

research area is polymer blends/composites/nanocomposites, nanomaterials and characterization of materials.

Yuvraj S. Negi received Ph.D. in Polymer Science from Indian Institute of Technology Delhi, India in 1983. He was postdoctoral fellow in Tokyo Institute of Technology in 1985. Presently, he is Faculty of Polymer Science and Technology at Indian Institute of Technology Roorkee, India. $\mathrm{He}$ has been involved in Polymer Science, Technology and Engineering research for the last twenty five years. $\mathrm{He}$ has contributed several patents and publications in international journals of repute.

U.P. Mulik received his $\mathrm{PhD}$ in Polymer Chemistry from the National Chemical Laboratory (NCL), Pune, India, in 1982. He worked with Goodlass Nerolac Paints Ltd. for one year and subsequently with Incab Industries Ltd. till 1993. He joined Centre for Materials for Electronics Technology(C-MET), Pune in December 1993 where currently, he is Scientist ' $E$ '. He is Life member of the Society for Polymer Science, India and Materials Research Society of India. Recently (2007-2008), he has worked as a Brain-Pool Visiting Scientist at Korea Research Institute of Chemical Technology, Daejon, Korea. He has published over 40 papers in international journals and more than 60 oral/poster presentations in various national/international symposia. His current research interests include photosensitive polymers, photoimageable pastes (Thick film/plasma display), polymer nanocomposites and materials for renewable energy.

Jagdish W. Dadge received Ph.D. in Physics from University of Pune, India in 2007. He was a Postdoctoral fellow at Catholic University, Belgium. Presently, he is Assistant Professor in the Department of Physics, College of Engineering Pune. His main research interests are nonlinear optical properties of nanomaterials and chromophore doped polymers.

\section{Introduction}

Polymeric guest-host systems have been emerged as strong candidates for various futuristic optoelectronic devices in comparison to their inorganic counterparts due to their large optical non-linearity, lower dielectric constant, ultrafast and broadband electronic responses. They provide durability, environmental protection and packaging advantages that are not provided by inorganic nonlinear optical (NLO) materials. Moreover, they are easier to prepare and process than the inorganic counterpart such as $\mathrm{LiNbO}_{3}$.

High speed communication in the high technology computer fields is achieved via optical interconnections based on the application of a poled guest-host system in which a NLO guest molecule is incorporated into an organic host polymer matrix. The guest-host system is basically an inter- and intra-molecular interactive system, which retain permanent dipole ordering with careful control of poling above glass transition temperature $\left(\mathrm{T}_{\mathrm{g}}\right)$. Poling above the $T_{g}$ alters the random orientation of the NLO molecules in the polymer film and develops a net alignment of molecules in the polymer film. The polymeric guest-host systems derive their NLO properties from the hyperpolarizability of chromophores [1-4]. Singer et al. reported the second order nonlinear coefficient $\left(\mathrm{d}_{33}\right)$ of azo dye disperse red (DR1) doped poly(methyl methacrylate) (PMMA) approximately five times that of potassium dihydrogen phosphate (KDP) [5]. Subsequently, they have studied the relaxation behaviour in SHG at various temperatures [6]. Having et al. reported the electrochroism of dye polymer mixtures consisting of a small amount of dye dissolved in PMMA and poled above the $\mathrm{T}_{\mathrm{g}}$ of polymer [7]. The major problem of the guest-host system is the relaxation (decay) of the electro-optic activity with time. The relaxation behaviour of 2-methyl-4-nitroaniline (MNA) doped PMMA has been discussed [8].

The organic m-nitroaniline (m-NA) is well known for its nonlinear and electro-optic effects [9-13]. Therefore, recently we have investigated the thermal, structural and second harmonic generation (SHG) properties of m-NA doped PMMA films as a function of m-NA concentration [11]. The SHG is a NLO process that results in the conversion of an input coherent optical wave into an output coherent wave of twice the input frequency having same pulse width as that of input wave and optical intensity is proportional to the square of the input intensity. To the best of our knowledge, first time we report the effect of poling temperature on SHG intensity and relaxation of SHG intensity at room temperature with respect to time.

\section{Experimental}

\section{Preparation of freestanding films}

Optical grade PMMA was synthesized by the method reported in previous paper [11]. The inherent viscosity of PMMA determined by Ubblohde viscometer was $0.50 \mathrm{dl} / \mathrm{g}$, which indicates the film forming property. Tough, transparent and flexible films of PMMA doped with 10, 20 and $30 \mathrm{wt} \%$ sublimed m-NA were prepared by solution cast method using toluene as solvent. The solvent was allowed to evaporate under ambient conditions until the film hardens. The film were then removed and placed in vacuum oven for $4-5 \mathrm{~h}$ at $100{ }^{\circ} \mathrm{C}$ to remove all residual solvent. After drying colored transparent films were obtained and subjected to optical and thermal studies. To align the NLO active m-NA molecule in the amorphous matrix a contact electrode poling of doped films was carried out. For this controlled and doped polymer films were heated from room temperature to 100,120 and $140{ }^{\circ} \mathrm{C}$. The sample was poled for $30 \mathrm{~min}$ at a given poling temperature with an applied dc electric field of $5 \mathrm{KV} / \mathrm{cm}$. The samples were then cooled to room temperature and the poling field was subsequently removed, which results in a system where the dipole moment of m-NA guest molecule is aligned in the electric field direction within the PMMA host matrix. 


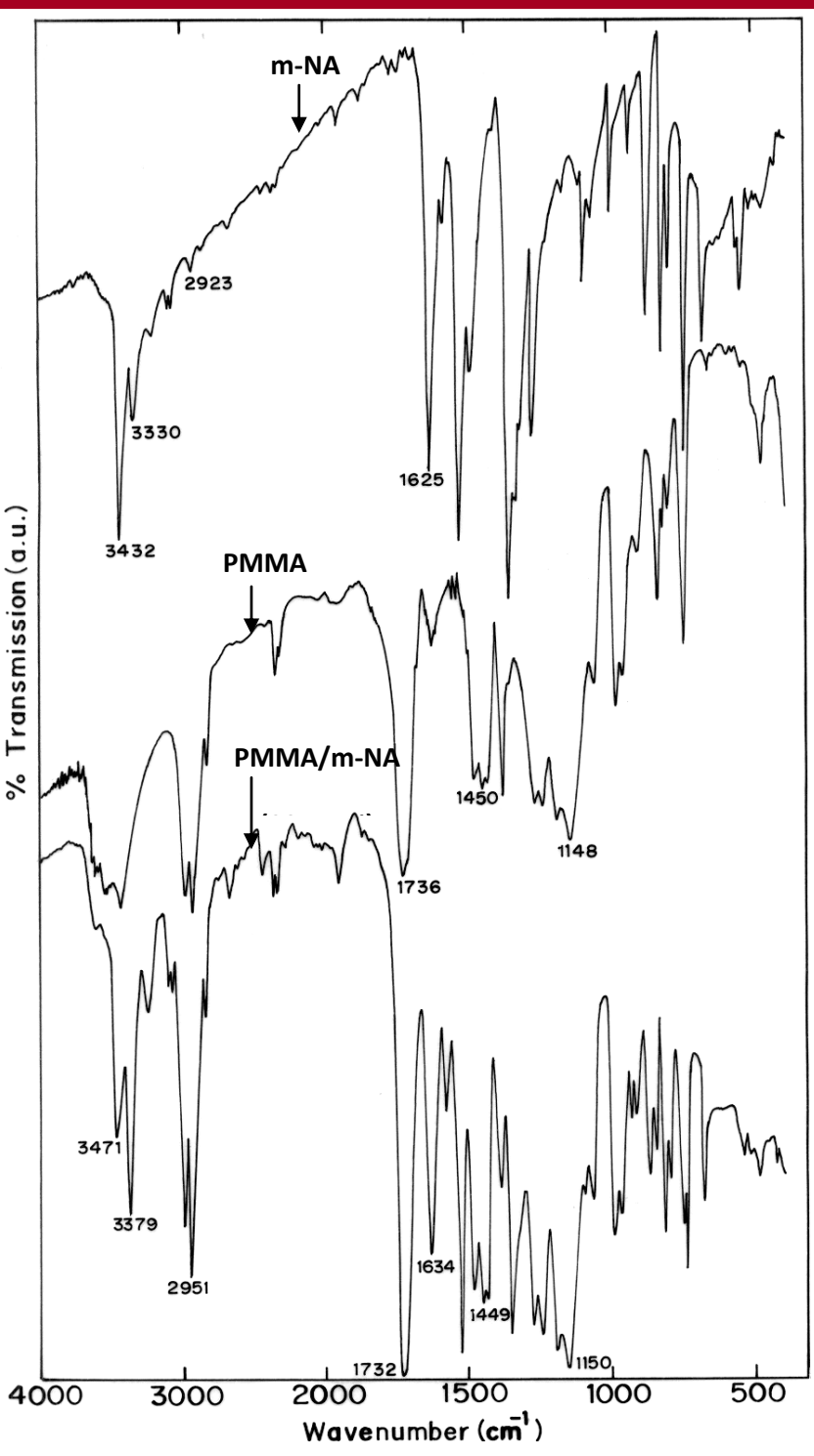

Fig. 1. FTIR spectra of m-NA, PMMA and m-NA doped PMMA freestanding films.

\section{Characterization of doped films}

The FTIR spectra of m-NA, PMMA and $20 \mathrm{wt} \% \mathrm{~m}-\mathrm{NA}$ doped PMMA films were recorded on Perkin-Elmer FTIR spectrometer (SPECTRUM 2000). The scanning range is from 4000 to $400 \mathrm{~cm}^{-1}$. This was carried out to find out the type of interactions between the m-NA and PMMA molecules. The isothermal thermogravimetric analysis (TGA) of the samples was conducted on a Mettler-Toledo $851^{\mathrm{e}}$ at 120 and $140{ }^{\circ} \mathrm{C}$ for 60 minutes in air atmosphere. This was carried out to check the thermal stability of the $\mathrm{m}$ NA doped PMMA films at poling temperature and time. The effect of m-NA doping on glass transition temperature $\left(\mathrm{T}_{\mathrm{g}}\right)$ of PMMA was studied on DuPont Instruments 910 DSC. The samples placed in an aluminum pan were heated from $30{ }^{\circ} \mathrm{C}$ to $300{ }^{\circ} \mathrm{C}$ at a heating rate of $10{ }^{\circ} \mathrm{C} / \mathrm{min}$ in nitrogen atmosphere. For evaluating SHG intensity, poled m-NA doped PMMA films were illuminated with a Qswitched Nd: YAG laser (wavelength $1064 \mathrm{~nm}$, pulse width $40 \mathrm{~ns}$ and 1pps) beam. The generated SHG signal at 532 $\mathrm{nm}$ was separated from the fundamental wave by using filters. SHG signal was measured relative to urea. SHG signal of the poled films was measured as a function of laser input energy and poling temperatures using the experimental set-up as reported elsewhere [14].

\section{Results and discussion}

The FTIR spectra of m-NA, PMMA and doped freestanding films are shown in Fig. 1. Characteristic absorption bands of m-NA are obtained at 3432, 3330 ($\left.\mathrm{NH}_{2}{ }^{-}\right), 2923(-\mathrm{NH}-), 1625\left(-\mathrm{NH}_{2}{ }^{-}\right), 1523$ and $1349 \mathrm{~cm}^{-1}$. FTIR peaks at 3330 and $3432 \mathrm{~cm}^{-1}$ is corresponding to symmetric and asymmetric stretching modes of free $\mathrm{NH}_{2}$ group, respectively. The peak at $2923 \mathrm{~cm}^{-1}$ is due to $\mathrm{N}-\mathrm{H}$ stretching mode. $\mathrm{NO}_{2}$ stretching modes are observed at 1524 and $1349 \mathrm{~cm}^{-1}$. Absorption bands of PMMA at 1148, 1450, 1736 and 2953 are due to ether band, C-H bending of $\mathrm{CH}_{2}$ group, carbonyl group and $\mathrm{C}-\mathrm{H}$ stretching, respectively. As shown in Fig. 1, there is significant shift in the carbonyl band from 1736 to $1717 \mathrm{~cm}^{-1}$ of PMMA. Symmetric stretching of $\mathrm{NH}_{2}$ is shifted from 3330 to 3379 $\mathrm{cm}^{-1}$. Asymmetric stretching of $\mathrm{NH}_{2}$ group shifted from 3432 to $3471 \mathrm{~cm}^{-1}$. The significant shifting of these bands suggests a hydrogen bonding formation between the amino group of m-NA and the carbonyl group of PMMA. The mNA doped PMMA films also show additional bands in the region of 3220 to $3250 \mathrm{~cm}^{-1}$. This may be due to hydrogen bonding between m-NA and PMMA. It is also noted that the $\mathrm{N}-\mathrm{H}$ stretching mode at $2923 \mathrm{~cm}^{-1}$ is disappeared [11].

Fig. 2 shows loss of weight at poling temperatures as a function of time (seconds) for pure m-NA and $20 \mathrm{wt} \% \mathrm{~m}$ NA doped PMMA films. Since for poling, m-NA doped PMMA films were heated at 100,120 , and $140{ }^{\circ} \mathrm{C}$ for 30 minutes under applied constant electric field. Therefore, thermal stability of the m-NA and m-NA doped films were determined at these poling temperatures to know the loss of m-NA during poling. As shown in Fig. 2, the weight loss of m-NA run at $120{ }^{\circ} \mathrm{C}$ for 30 minutes is about $16 \%$ whereas loss of m-NA run at $140{ }^{\circ} \mathrm{C}$ for 30 minutes is about $20 \%$. The weight loss may be attributed to the sublimation of m-NA molecules. The weight loss for $20 \mathrm{wt} \% \mathrm{~m}-\mathrm{NA}$ doped PMMA film run at $120{ }^{\circ} \mathrm{C}$ for 30 minutes is only about $2.2 \%$. This shows substantial improvement in thermal stability of the doped films compared to that of pure m-NA crystals.

As shown in Fig. 3, pure PMMA has $T_{g}$ at $123.7^{\circ} \mathrm{C}$ and $\mathrm{T}_{\mathrm{g}}$ of doped PMMA films did not change significantly. This is in contrast to 4-(N,N-dimethylamino)-4'nitrostilbene (DANS) doped polycarbonate films, which shows decrease in $T_{g}$ with increasing DANS content [15]. This may be due to the two contradictory mechanisms. First, formation of hydrogen bonding between m-NA and PMMA may lead to increase in $T_{g}$. Secondly; presence of m-NA probably decreases the bonding between the PMMA molecules which might be the reason of decreasing $T_{\mathrm{g}}$. The resultant of these two factors probably gives no change in $\mathrm{T}_{\mathrm{g}}$ in present work. Moreover, absence of endothermic peak of $\mathrm{m}$-NA shows that there is no phase separation of m-NA in PMMA host up to $30 \mathrm{wt} \% \mathrm{n}-\mathrm{NA}$. This was also confirmed from X-ray diffraction as reported elsewhere [11]. 


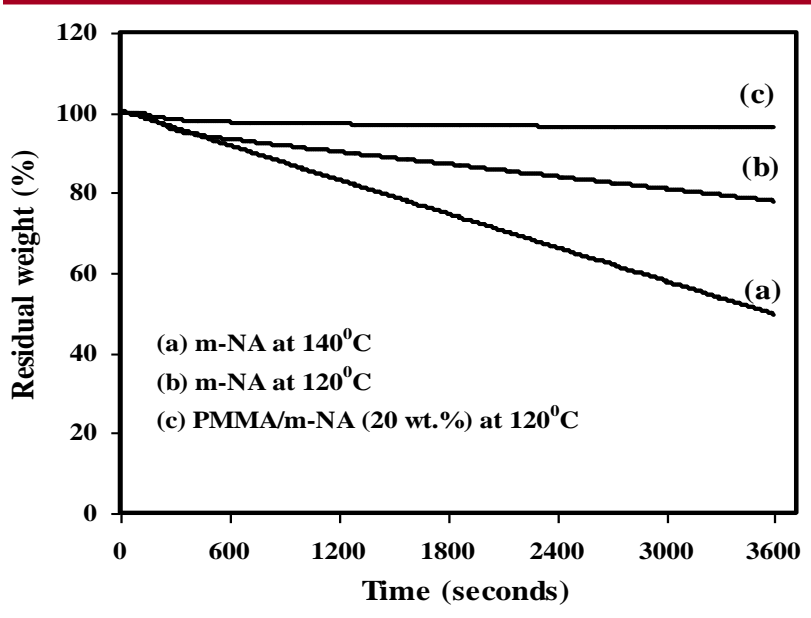

Fig. 2. Isothermal TGA run of pure m-NA (a and b) and 20 wt. \% m-NA doped PMMA film (c) in air atmosphere.

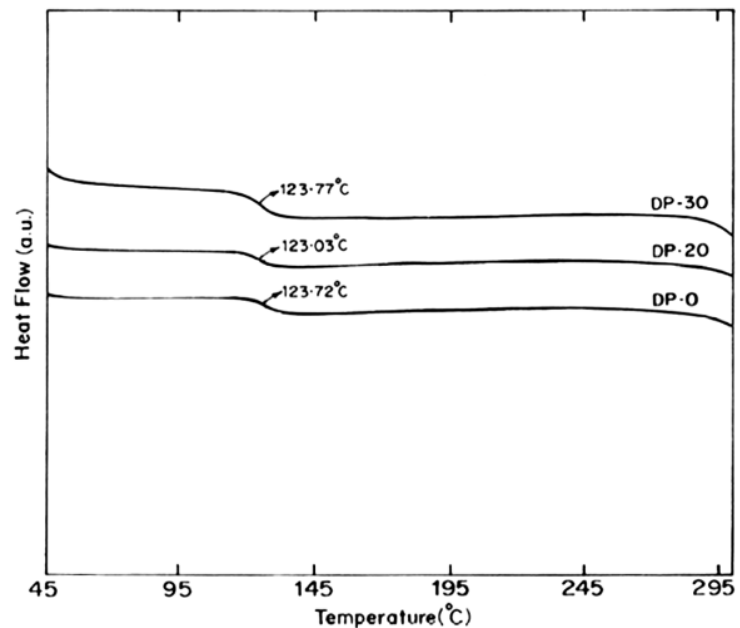

Fig. 3. DSC heating curves for pure PMMA (DP-0), $20 \mathrm{wt} \% \mathrm{~m}-\mathrm{NA}$ (DP20) and $30 \mathrm{wt} \% \mathrm{~m}-\mathrm{NA}$ (DP-30) doped PMMA films.

Figs. 4 and 5 shows the SHG intensity of $10 \mathrm{wt} \%$ and $30 \mathrm{wt} \% \mathrm{~m}-\mathrm{NA}$ doped PMMA films after poling at three temperatures, i.e., 100,120 , and $140{ }^{\circ} \mathrm{C}$, respectively. As the input energy increases from 6 to $18 \mathrm{~mJ}$, the SHG intensity increases. It can be seen that films poled at 100 and $120{ }^{\circ} \mathrm{C}$ did not show significant differences in SHG signal intensity because both the poled temperatures were lower than $\mathrm{T}_{\mathrm{g}}$. The film poled above $\mathrm{T}_{\mathrm{g}}$, i.e., $140{ }^{\circ} \mathrm{C}$, showed highest SHG intensity among the films poled at various temperatures. This is attributed to the increased mobility of m-NA molecules as the temperature is increased and thus, higher number of molecules is aligned in the PMMA matrix.

The isothermal decay or relaxation in SHG intensity as a function of time (in hours) for a series of laser input energy for $20 \mathrm{wt} \% \mathrm{~m}-\mathrm{NA}$ doped PMMA film poled at 120 ${ }^{\circ} \mathrm{C}$ for 30 minutes is shown in Fig. 6. It can be seen that SHG intensity decreases as the decay time is increased. The rate of decay is fast up to $50 \mathrm{~h}$, thereafter, the decay rate is decreased. This is similar to the trends of DR-1 doped PMMA films [6]. The decrease in SHG intensity with time may be attributed to the relaxation of m-NA molecules from thermodynamically unstable (poled) state to the thermodynamically equilibrium state. In other words m-NA molecules try to come from preferential oriented direction to random directions. Hence, SHG intensity decreases with time. However, the retained SHG intensity is more than 50 $\%$ of its original intensity after one week, which is comparable to that of DR-1 doped PMMA guest-host system [6].

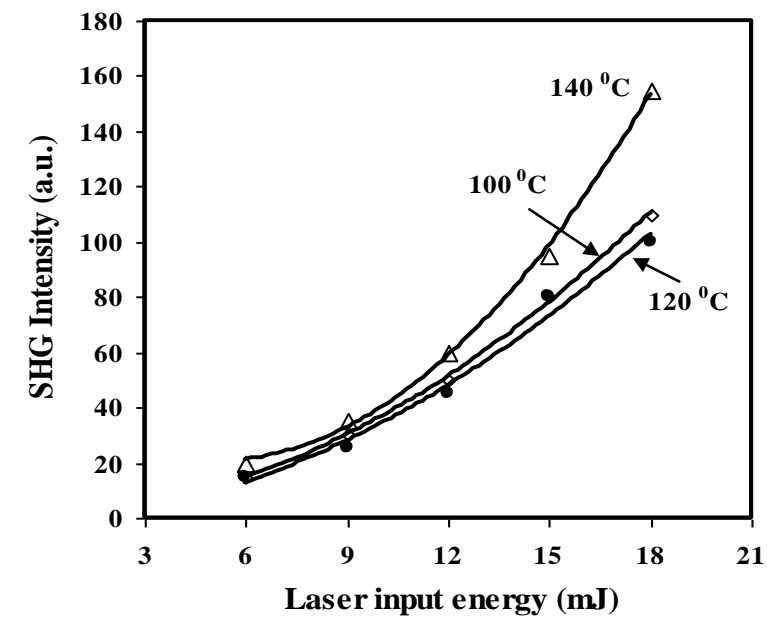

Fig. 4. SHG intensity as a function of laser input energy for $10 \mathrm{wt} \% \mathrm{~m}$ NA doped PMMA film after poling at 100,120 , and $140^{\circ} \mathrm{C}$ for $30 \mathrm{~min}$.

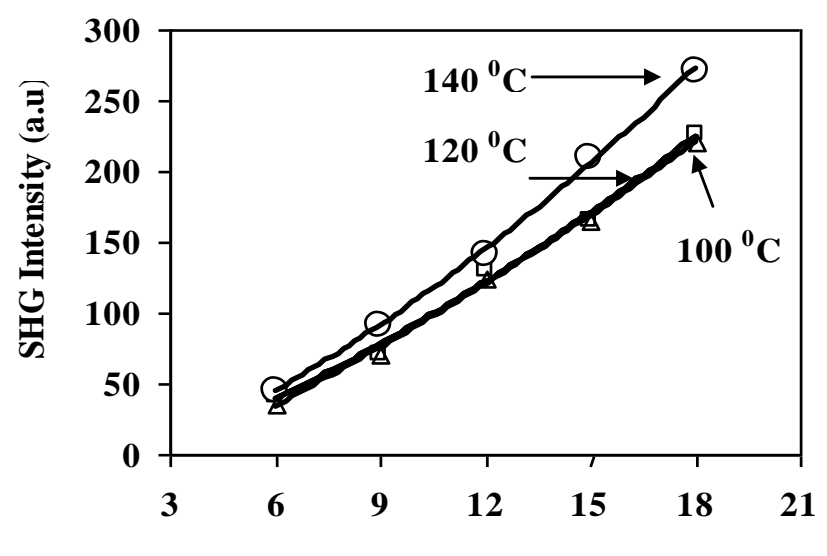

Laser Input Energy (mJ)

Fig. 5. SHG intensity as a function of laser input energy for $30 \mathrm{wt} \% \mathrm{~m}$ NA doped PMMA film after poling at 100,120 , and $140^{\circ} \mathrm{C}$ for $30 \mathrm{~min}$.

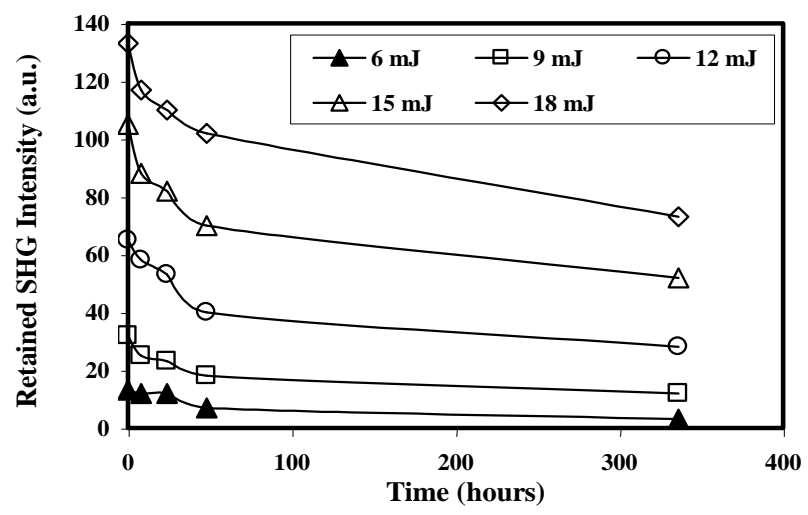

Fig. 6. Isothermal relaxation in SHG intensity with time (hours) at various laser input energy for $20 \mathrm{wt} \% \mathrm{~m}$-NA doped PMMA film poled at $120^{\circ} \mathrm{C}$ for $30 \mathrm{~min}$. 


\section{Conclusion}

Freestanding films of m-NA doped PMMA guest-host system were prepared successfully. The isothermal thermal stability of m-NA doped PMMA film was improved significantly as compared to m-NA guest. SHG signal intensity of films poled at $140{ }^{\circ} \mathrm{C}$ is higher than that of films poled at 100 and $120^{\circ} \mathrm{C}$ for 30 minutes. For the poled films, SHG intensity decreases with relaxation time due to the relaxation of m-NA molecules from unstable thermodynamic state to equilibrium state. The SHG intensity of 20 wt. \% m-NA doped PMMA film remained about $50 \%$ of its original intensity after one week.

\section{Acknowledgement}

Authors are grateful to Mrs. Shany Joseph for her help in samples analysis.

\section{References}

1. Lee, M.; Katz, H.E.; Erben, C.; Gill, D.M.; Herber, J. D., McGee, D.J. Science 2002, 298, 1401.

2. Chen, L.T.; Tam W.; Marder, S.R.; Stiegmas, A. E.; Rikken, G.; Spangler, C.W. J. Phys. Chem. 1991, 95, 10631.

3. Chen, L.T.; Tam, W.; Marder, S.R.; Stiegmas, A.E.; Rikken, G.; Spangler, C.W. J. Phys. Chem. 1991, 95, 10641.

4. Dalton, L. Polymers for Photonics Applications I: Advances in Polym. Sci. 2002, 158, 1.

5. Singer, K.D.; Sohn, J.E.; Lalama, S.J. Appl. Phys. Lett. 1986, 49, 248.

6. Singer, K.D.; King, L.A. J. Appl. Phys. 1991, 70, 3251.

7. Having, E.E.; Bunsenges P.P. Van Ber. Phys. Chem. 1979, 83, 816.

8. Ray, P.C.; Das, P.K. Eur. Polym. J. 1996, 32, 51.

9. Bergiman, J.G.; Crane, G.R. J. Chem. Phys. 1977, 66, 3803.

10. Oudar, J.L.; Chemia, D.S. J. Chem. Phys. 1977, 66, 2664.

11. Goyal, R.K.; Damkale, S.R.; Adhyapak, P.V.; Jagdish, D.; Aiyer, R.C.; Negi. Y.S. In. J. Plast. Technol. 2004, 8, 249.

12. Sureshkumar, M.S.; Goyal, R.K.; Negi, Y.S. Polym. Adv. Technol. 2010, 21,1 .

13. Chen, L.; Pang, X.; Yu, G.; Zhang, J. Adv. Mater. Lett. 2010, 1, 75.

14. Pethkar, S.; Dhamadhikari, J.A., Athawale, A.A., Aiyer, R.C.; Vijayamohanan, K. J. Phys. Chem. B. 2001, 105, 5110.

15. Wafa, A.M.A. El; Okada, S.; Nakanishi, H. Dyes and Pigments 2006 , $69,239$. 